\title{
A ATUAÇÃo DA LIDERANÇA DE ENFERMAGEM COMO ESTRATÉGIA NA PREVENÇÃO DOS IMPACTOS DA PANDEMIA NA SAÚDE MENTAL DOS COLABORADORES
}

\section{REVISÃO INTEGRATIVA}

NUNES, Barbara Aparecida de Souza ${ }^{1}$, SHIMIZU, Juliana Cristina ${ }^{2}$, PORFIRIO, Regiane Baptista Martins ${ }^{3}$

NUNES, Barbara Aparecida de Souza. SHIMIZU, Juliana Cristina. PORFIRIO, Regiane Baptista Martins. A atuação da liderança de enfermagem como estratégia na prevenção dos impactos da pandemia na saúde mental dos colaboradores. Revista Científica Multidisciplinar Núcleo do Conhecimento. Ano 06, Ed. 06, Vol. 12, pp. 27-39. Junho de 2021. ISSN: 2448-0959, Link de acesso: https://www.nucleodoconhecimento.com.br/saude/atuacao-da-lideranca, $\quad$ DOI: 10.32749/nucleodoconhecimento.com.br/saude/atuacao-da-lideranca

\section{RESUMO}

Objetivo: Identificar, na literatura nacional e internacional, o impacto direto ou indireto das lideranças de equipes de enfermagem, de maneira positiva ou negativa, que foram intensificadas em meio pandemia de COVID-19 impactando na saúde mental dos profissionais. Pergunta problema: Como as lideranças de enfermagem podem atuar de forma a prevenir os impactos causados pela pandemia na saúde mental dos profissionais de enfermagem? Metodologia: Trata-se de uma pesquisa baseada na revisão integrativa de literatura a respeito do impacto da liderança na saúde mental dos profissionais de enfermagem durante a pandemia. Os resultados foram planificados e constituíram a tabela 2 que se estrutura em colunas contendo: Autores, Ano de publicação, Periódico, Título do estudo e Objetivo do estudo. Resultados: O

\footnotetext{
${ }^{1}$ Graduandas de Enfermagem.

${ }^{2}$ Graduandas de Enfermagem.

${ }^{3}$ Orientadora.
} 
objetivo desse estudo foi alcançado, onde foi possível identificar na literatura, os impactos gerados pela liderança das equipes de enfermagem, de maneira negativa na qual um líder sem experiência, que não consegue desenvolver a comunicação efetiva e compreender sua equipe, e engendrando sobrecarga de trabalho, gerando insegurança, desgaste emocional e físico, conflitos entre os profissionais acarretada pela pressão da pandemia COVID-19 ao contrário de uma liderança preparada pois é necessário saber liderar em um momento complexo de pandemia afins de minimizar o estresse de uma profissão que por si só é indutora de estresse.

Palavras-chave: Enfermagem, Gestão, Liderança, Pandemia, Saúde Mental.

\section{INTRODUÇÃO}

A Organização Mundial da Saúde (OMS) declarou pandemia o novo Coronavírus Severe Acute Respiratory Syndrome Coronavirus 2 (SARS-Cov2) no dia 11 de março de 2020, quando teve o primeiro caso registrado em Wuhan na China no dia 31 de dezembro de 2019. Trata-se de uma doença viral, altamente infectante, caracterizada por ter um alto nível de disseminação através de gotículas (BRASIL, 2020).

A maior parte dos infectados apresentam sintomas leves como: febre, tosse seca e cansaço, não precisando de hospitalização; sendo outros assintomáticos. Contudo, existem pacientes que estão em um cenário mais grave e podem ter uma rápida evolução da doença tendo, o paciente, que ser submetido à Unidade de Terapia Intensiva (UTI) em ventilação mecânica (HOLANDA; PINHEIRO, 2020).

Conforme site Coronavírus Brasil (MINISTÉRIO DA SAÚDE, 2020) registros evidência que ainda em dezembro de 2020 já ultrapassamos mais de 6.487 .084 casos confirmados.

A equipe de enfermagem é uma das que vem atuando exaustivamente na linha de frente dos hospitais junto aos portadores do COVID-19, contudo, demonstrou aumento significativo de transtornos mentais como depressão, ansiedade e estresse que estão relacionados às condições de trabalho que se conectam diretamente ao gestor e o 
próprio funcionário; outros fatores estão ligados à alta rotatividade de profissionais, sobrecarga de trabalho e déficit de profissionais, tornando-se situações que podem levar a desmotivação profissional ocasionando cenários de negligência, imprudência, falta de informação e até mesmo distração que acarreta em erros (HUMERES; OHL; SILVA, 2020).

Uma pesquisa realizada pela Universidade do Oeste Paulista (Unoeste) juntamente com Conselho Regional de Enfermagem de São Paulo (COREN-SP) avaliou 13.587 profissionais de enfermagem, entre eles enfermeiros, técnicos e auxiliares de enfermagem. $\mathrm{O}$ objetivo do estudo foi identificar os impactos psicológicos durante a pandemia do coronavírus, visto que os resultados demonstraram que $87 \%$ desses trabalhadores são mulheres com média de idade de 38 anos. Destacando que $80 \%$ dos participantes estão em contato como suspeitos ou confirmados de COVID-19 no trabalho; $87 \%$ afirmaram ter sintomas de Burnout, 58\% com ansiedade leve, moderada ou severa; $93 \%$ com medo de transmitir a doença para as pessoas que amam; apenas 14\% estão realizando tratamento psicológico. (COREN-SP, 2020)

Dado que uma boa liderança precisa estimular a proatividade e engajamento da sua equipe, visando também pela promoção e bem-estar do seu time, consequentemente mesmo diminui os impactos negativos na assistência e saúde mental dos trabalhadores tornando-se um motivo que potencializa ações positivas influenciando diretamente nos resultados, além de gerar melhoria da qualidade de vida dos membros de sua equipe. (FERREIRA; DALL'AGNOL; PORTO, 2016).

Assim sendo, o questionamento norteador desse estudo é: Como as lideranças de enfermagem podem atuar de forma a prevenir os impactos causados pela pandemia na saúde mental dos profissionais de enfermagem?

O estudo tem como objetivo identificar, na literatura nacional e internacional, o impacto direto ou indireto das lideranças das equipes de enfermagem, de maneira positiva ou negativa, e que pode impactar na saúde mental dos trabalhadores e intensificado em meio a pandemia do COVID-19. 


\section{METODOLOGIA}

\section{TIPO DE PESQUISA}

Trata-se de uma pesquisa baseada na revisão integrativa de literatura a respeito do impacto da liderança na saúde mental dos profissionais de enfermagem durante a pandemia.

Revisão integrativa que é um método complexo no qual proporcionam a garantia de uma pesquisa cientifica eficaz garantindo sua elegibilidade a partir de evidências encontradas (SOARES e col, 2014)

\section{OPERACIONALIZAÇÃO DA COLETA DE DADOS}

A coleta de dados foi realizada de julho a outubro de 2020 e se deu por meio da leitura dos resumos de artigos científicos publicados até 2020. As bases de dados utilizadas foram: Scientific Electronic Library Online (SciELO,Biblioteca Virtual em Saúde (BVS), Sites do COREN-SP, CORONAVÍRUS BRASIL do Ministério da Saúde, BRASIL. Utilizou-se os descritores em ciências da saúde (DeCS): Enfermagem; Gestão; Liderança; Pandemia; Saúde Mental.

Os critérios de inclusão utilizados foram: Artigos em língua portuguesa e espanhola; aqueles que traziam resultados recentes relacionados à pandemia COVID-19; o impacto da pandemia na saúde do trabalhador; que tratam de pesquisas relacionadas ao sofrimento mental do profissional; e como uma liderança pode impactar negativa e positivamente no trabalho diário de sua equipe.

Inicialmente foram selecionados 73 artigos e um livro. Foram lidos os resumos dos mesmos e, considerando os critérios de inclusão, ficaram 18 sendo três excluídos por serem duplicados, totalizando 15 artigos e um livro, conforme denota a tabela 1. 
Tabela 1. Demonstração de dados utilizados para levantamento cientifico para estudo

\begin{tabular}{|c|c|c|}
\hline \multicolumn{3}{|l|}{ LEVANTAMENTO BIBLIOGRAFICO } \\
\hline \multirow{2}{*}{$\begin{array}{l}\text { LEVANTAMENTO BIBLIOGRAFICO } \\
\text { SITES E LIVROS }\end{array}$} & \multirow[t]{2}{*}{ № } & № $\quad$ APÓs \\
\hline & & EXCLUSÃO \\
\hline Scientific Electronic Library Online (SciELO) & 56 & 10 \\
\hline Biblioteca Virtual em Saúde (BVS) & 9 & 0 \\
\hline Site COREN-SP & 1 & 1 \\
\hline Site CORONAVÍRUS BRASIL & 1 & 1 \\
\hline Revista Cogitare Enfermagem - UFPR. & 2 & 1 \\
\hline Revista Comunicação Em Ciências Da Saúde - CCS & 1 & 0 \\
\hline Jornal Brasileiro de Pneumonia & 1 & 1 \\
\hline Ministério da Saúde BRASIL & 1 & 1 \\
\hline $\begin{array}{l}\text { O Monge e o Executivo Uma história sobre a essência } \\
\text { da Liderança }\end{array}$ & 1 & 1 \\
\hline TOTAL & 73 & 16 \\
\hline
\end{tabular}

Fonte: Elaborado pelas autoras.

\section{RESULTADOS}

Os resultados foram planificados e compuseram a tabela 2 que se estrutura em colunas contendo: Autoria, Ano de publicação, Periódico, Título do estudo e Objetivo do estudo.

Tabela 2. Base de análise de características de artigos utilizados.

\begin{tabular}{|l|l|l|l|l|} 
Autoria & $\begin{array}{l}\text { Ano de } \\
\text { publicaçã } \\
0\end{array}$ & Periódico & Título do estudo & $\begin{array}{l}\text { Objetivo do } \\
\text { estudo }\end{array}$ \\
\end{tabular}




\begin{tabular}{|c|c|c|c|c|}
\hline $\begin{array}{l}\text { Hunter, C } \\
\text { J }\end{array}$ & 2004 & $\begin{array}{l}\text { Editora } \\
\text { Sextante }\end{array}$ & $\begin{array}{l}\text { LIVRO: O Monge e o } \\
\text { Executivo uma } \\
\text { história sobre a } \\
\text { essência } \\
\text { Liderança }\end{array}$ & $\begin{array}{l}\text { Liderança } \\
\text { aspectos morais } \\
\text { e éticos. }\end{array}$ \\
\hline $\begin{array}{l}\text { Ferreira, } \\
\text { EG e col }\end{array}$ & 2016 & $\begin{array}{l}\text { Escola Anna } \\
\text { Nery }\end{array}$ & $\begin{array}{ll}\text { Repercussões } & \text { da } \\
\text { proatividade } & \text { no } \\
\text { gerenciamento } & \text { do } \\
\text { cuidado: } & \\
\text { Percepções } & \text { de } \\
\text { enfermeiro } & \end{array}$ & $\begin{array}{ll}\text { Analisar } & \text { e } \\
\text { conhecer as } \\
\text { percepções de } \\
\text { enfermeiros } \\
\text { acerca da } \\
\text { proatividade no } \\
\text { gerenciamento } \\
\text { do cuidado. }\end{array}$ \\
\hline $\begin{array}{l}\text { Carvalho, } \\
\text { AGF e col }\end{array}$ & 2016 & $\begin{array}{l}\text { Acta Paulista } \\
\text { de } \\
\text { Enfermagem }\end{array}$ & $\begin{array}{l}\text { Liderança autêntica } \\
\text { e perfil pessoal e } \\
\text { profissional de } \\
\text { enfermeiros }\end{array}$ & $\begin{array}{l}\text { Analisar } \\
\text { liderança } \\
\text { autentica na } \\
\text { enfermagem. }\end{array}$ \\
\hline $\begin{array}{l}\text { Duarte, } \\
\text { MLC. e col }\end{array}$ & 2018 & $\begin{array}{l}\text { Revista } \\
\text { Gaucha de } \\
\text { Enfermagem }\end{array}$ & $\begin{array}{lr}\text { O trabalho em } \\
\text { emergência } & \\
\text { hospitalar: } & \\
\text { sofrimento } & \text { e } \\
\text { estratégias } & \\
\text { defensivas } & \text { dos } \\
\text { enfermeiros } & \end{array}$ & $\begin{array}{l}\text { Analisar fatores } \\
\text { de sofrimento e } \\
\text { estratégias } \\
\text { defensivas dos } \\
\text { enfermeiros que } \\
\text { atuam em uma } \\
\text { emergência de } \\
\text { um hospital } \\
\text { universitário. }\end{array}$ \\
\hline $\begin{array}{l}\text { Gonçalves } \\
\text {, AR e col }\end{array}$ & 2018 & $\begin{array}{l}\text { Revista } \\
\text { Portuguesa de } \\
\text { Enfermagem } \\
\text { de Saúde } \\
\text { Mental }\end{array}$ & $\begin{array}{lr}\text { Stress } & \text { e } \\
\text { engajamento } & \text { na } \\
\text { profissão } & \text { de } \\
\text { enfermagem: anális }\end{array}$ & $\begin{array}{lr}\text { Analisar as } \\
\text { dimensões do } \\
\text { stress } \\
\text { engajamento. }\end{array}$ \\
\hline
\end{tabular}

RC: 89084

Disponível em: https://www.nucleodoconhecimento.com.br/saude/atuacao-dalideranca 


\begin{tabular}{|c|c|c|c|c|}
\hline & & & $\begin{array}{l}\text { e de dois contextos } \\
\text { internacionais }\end{array}$ & \\
\hline $\begin{array}{l}\text { Forte, ECN } \\
\text { e col }\end{array}$ & 2019 & $\begin{array}{l}\text { Revista de } \\
\text { Enfermagem } \\
\text { da USP }\end{array}$ & $\begin{array}{lr}\text { Processo } & \text { de } \\
\text { trabalho: } & \\
\text { fundamentação } & \text { para } \\
\text { compreender } & \text { os } \\
\text { erros } & \text { de } \\
\text { enfermagem* } & \end{array}$ & $\begin{array}{ll}\text { Analisar } & \mathrm{e} \\
\text { compreender } & \mathrm{o} \\
\text { processo de } & \\
\text { erros. } & \end{array}$ \\
\hline $\begin{array}{l}\text { Oliveira, } \\
\text { DM e col }\end{array}$ & 2019 & $\begin{array}{l}\text { Revista } \\
\text { Cuidarte }\end{array}$ & $\begin{array}{l}\text { Afastamento do } \\
\text { trabalho por } \\
\text { transtornos mentais } \\
\text { e comportamentais } \\
\text { entre profissionais } \\
\text { de enfermagem }\end{array}$ & $\begin{array}{l}\text { Analisar como } \\
\text { Transtornos } \\
\text { mentais e } \\
\text { comportamentai } \\
\text { s afeta o } \\
\text { profissional de } \\
\text { enfermagem. }\end{array}$ \\
\hline $\begin{array}{l}\text { Silva, } \\
\text { AEBC e } \\
\text { col }\end{array}$ & 2019 & $\begin{array}{l}\text { Revista de } \\
\text { Enfermagem } \\
\text { da USP }\end{array}$ & $\begin{array}{lr}\text { Avaliação do clima } \\
\text { de segurança do } \\
\text { paciente } & \text { em } \\
\text { unidades } & \text { de } \\
\text { internação } & \\
\text { hospitalar: um } & \\
\text { estudo transversal }\end{array}$ & $\begin{array}{ll}\text { Analisar } & \text { e } \\
\text { avaliar a } & \text { a } \\
\text { percepção de } \\
\text { enfermeiros de } \\
\text { diferentes } \\
\text { unidades de } \\
\text { internação de } \\
\text { um hospital de } \\
\text { ensino de Goiás } \\
\text { sobre o clima de } \\
\text { segurança do } \\
\text { paciente. }\end{array}$ \\
\hline $\begin{array}{l}\text { Koericha, } \\
\text { C e col }\end{array}$ & 2019 & $\begin{array}{l}\text { Revista } \\
\text { Gaucha de } \\
\text { Enfermagem }\end{array}$ & $\begin{array}{l}\text { Recursos } \\
\text { competências para } \\
\text { gestão de práticas } \\
\text { educativas por }\end{array}$ & $\begin{array}{l}\text { Analisar as } \\
\text { principais } \\
\text { competências }\end{array}$ \\
\hline
\end{tabular}




\begin{tabular}{|c|c|c|c|c|}
\hline & & & $\begin{array}{l}\text { enfermeiros: revisão } \\
\text { integrativa }\end{array}$ & $\begin{array}{l}\text { para gestão de } \\
\text { uma equipe. }\end{array}$ \\
\hline $\begin{array}{l}\text { Humerez, } \\
\text { DC e col }\end{array}$ & 2020 & $\begin{array}{l}\text { Revista } \\
\text { Cogitare } \\
\text { Enfermagem } \\
\text { UFPR. }\end{array}$ & $\begin{array}{l}\text { Saúde mental dos } \\
\text { profissionais de } \\
\text { enfermagem do } \\
\text { brasil no contexto da } \\
\text { pandemia covid-19: } \\
\begin{array}{l}\text { ação do conselho } \\
\text { federal de } \\
\text { enfermagem }\end{array}\end{array}$ & $\begin{array}{l}\text { Analisar a saúde } \\
\text { mental dos } \\
\text { profissionais de } \\
\text { enfermagem } \\
\text { meio pandemia } \\
\text { do COVID-19. }\end{array}$ \\
\hline $\begin{array}{l}\text { Veloz, AFV } \\
\text { e col }\end{array}$ & 2020 & $\begin{array}{l}\text { Health } \\
\text { Sciences }\end{array}$ & $\begin{array}{l}\text { Síndrome de } \\
\text { Burnouten } \\
\text { médicos/as } \\
\text { enfermeros/as } \\
\text { ecuatorianos } \\
\text { durante la pandemia } \\
\text { de coVID-19 }\end{array}$ & $\begin{array}{l}\text { Analisar como } \\
\text { síndrome de } \\
\text { Bournout } \\
\text { afetaram } \\
\text { enfermeiros } \\
\text { durante } \\
\text { pandemia. }\end{array}$ \\
\hline $\begin{array}{l}\text { Pereira, } \\
\text { MD e col }\end{array}$ & 2020 & $\begin{array}{l}\text { HumanScience } \\
\text { s }\end{array}$ & $\begin{array}{l}\text { Sofrimento } \\
\text { emocional dos } \\
\text { Enfermeiros no } \\
\text { contexto hospitalar } \\
\text { frente à pandemia } \\
\text { de COVID-19 }\end{array}$ & $\begin{array}{l}\text { Analisar a saúde } \\
\text { emocional dos } \\
\text { enfermeiros } \\
\text { frente a } \\
\text { pandemia. }\end{array}$ \\
\hline $\begin{array}{l}\text { Oliveira, } \\
\text { WA e col }\end{array}$ & 2020 & $\begin{array}{l}\text { Estudos de } \\
\text { Psicologia } \\
\text { (Campinas) }\end{array}$ & $\begin{array}{lr}\text { Impactos } & \\
\text { psicológicos } & \mathrm{e} \\
\text { ocupacionais } & \text { das } \\
\text { sucessivas } & \text { ondas } \\
\text { recentes } & \mathrm{de} \\
\text { pandemias } & \mathrm{em} \\
\text { profissionais } & \mathrm{da} \\
\text { saúde: } & \text { revisão }\end{array}$ & $\begin{array}{l}\text { Analisar os } \\
\text { fatores } \\
\text { associados ao } \\
\text { impacto } \\
\text { psicológico e } \\
\text { ocupacional das } \\
\text { recentes e } \\
\text { sucessivas }\end{array}$ \\
\hline
\end{tabular}




\begin{tabular}{|c|c|c|c|c|}
\hline & & & $\begin{array}{l}\text { integrativa e lições } \\
\text { aprendidas }\end{array}$ & $\begin{array}{l}\text { ondas de } \\
\text { pandemias em } \\
\text { profissionais de } \\
\text { saúde }\end{array}$ \\
\hline $\begin{array}{l}\text { Santos, } \\
\text { ER e col }\end{array}$ & 2020 & $\begin{array}{l}\text { Unoeste e } \\
\text { COREN-SP }\end{array}$ & $\begin{array}{l}\text { O Impacto da } \\
\text { Pandemia Covid-19 } \\
\text { na Saúde Mental } \\
\text { dos Profissionais de } \\
\text { Enfermagem do } \\
\text { Estado de São Paulo }\end{array}$ & $\begin{array}{lr}\text { Analisar } & \text { e } \\
\text { identificar } & \text { os } \\
\text { impactos } & \\
\text { psicologicos } & \\
\text { durante r a } \\
\text { pandemia do } \\
\text { coronavirus. }\end{array}$ \\
\hline $\begin{array}{l}\text { Holanda, } \\
\text { MA e col }\end{array}$ & 2020 & $\begin{array}{l}\text { Jornal } \\
\text { Brasileiro de } \\
\text { Pneumonia }\end{array}$ & $\begin{array}{lr}\text { Pandemia } & \text { por } \\
\text { COVID-19 } & \text { e } \\
\text { ventilação } & \\
\text { mecânica: } & \\
\text { enfrentando } & \text { o } \\
\text { presente, } & \\
\text { desenhando o futuro }\end{array}$ & $\begin{array}{l}\text { Enfrentamento } \\
\text { da ventilação } \\
\text { mecânica } \\
\text { pandemia } \\
\text { Covid-19. }\end{array}$ \\
\hline Brasil & 2020 & $\begin{array}{l}\text { Ministério da } \\
\text { Saúde BRASIL }\end{array}$ & $\begin{array}{l}\text { Sobre a doença: } \\
\text { COVID-19 }\end{array}$ & $\begin{array}{ll}\text { Tudo } & \text { sobre } \\
\text { doença } & \text { Covid- } \\
19 . & \end{array}$ \\
\hline
\end{tabular}

Fonte: Elaborado pelas autoras.

\section{DISCUSSÃO}

Nas 16 publicações utilizadas nesse estudo foram identificados que o sofrimento emocional dos profissionais da saúde, incluindo enfermeiros, técnicos, auxiliares e médicos é potencializado nas sucessivas ondas de pandemias. Esses profissionais vêm se deparando com inúmeros desafios frente à pandemia do COVID-19 enfrentando o medo de contrair e transmitir a doença, além de lidar com esgotamento emocional e a pressão imposta no seu dia a dia. (OLIVEIRA et al., 2020) 
Segundo a pesquisa realizada pela Universidade do Oeste Paulista (Unoeste) juntamente ao Conselho Regional de Enfermagem de São Paulo (COREN-SP) identificou-se que os profissionais estão totalmente expostos ao vírus e com isso vem sofrendo uma sobre carga intensa no ambiente de trabalho, uma vez que $87 \%$ afirmam possuir sintomas de Burnout que acaba gerando um distúrbio psíquico, envolvendo a ansiedade e esgotamento mental e físico. Com toda a situação caótica apenas 14\% dos entrevistados afirmam estar buscando ajuda com psicólogos para auxiliar no enfrentamento frente à pandemia do Coronavírus. (COREN-SP, 2020)

A situação pandêmica agravou os níveis de ansiedade, estresse, medo, ambiguidade, depressão e exaustão dos profissionais de enfermagem. (HUMERES; OHL; SILVA, 2020). Esses profissionais que atuam na linha de frente estão representando o acréscimo significativo de casos da síndrome de Burnout, principalmente em enfermeiros e médicos, gerando cada vez mais profissionais adoecidos e afastados. Essas preocupações onde se referem o medo de contrair o vírus e o transmitir infectando seus entes queridos, acaba provocando alto nível de estresse e tristeza devido ao isolamento de seus familiares, amigos, além das mortes de colegas de profissão, ocasionado a mais insegurança e exaustão interferindo diretamente na assistência prestada ao paciente. (VELOZ et al., 2020)

É de extrema importância que os enfermeiros líderes, tenham um olhar ampliado para identificar os colaboradores que esteja passando por essa situação e assim concedam apoio, pois, havendo uma liderança que gere um comprometimento afetivo, com escuta ativa, empatia, ela consegue acolher esse profissional que necessita de cuidado, direcionando e incentivando a buscar ajuda de um especialista. Em contrapartida o líder também deve buscar estratégias na qual gere motivação e sentimento de valorização, acolhimento ocasionando comprometimento e confiança de seus liderados. (KOERICHA et al., 2019)

O líder necessita ter autocontrole, ser atencioso, apreciar e incentivar seus colaboradores, tratando todos como pessoas importantes, buscando 0 bem integralmente, certificando suas escolhas e outrossim contribuindo para o 
fortalecimento de sua gerência, prevenindo e minimizando os impactos negativos na saúde dos seus profissionais. Um líder de sucesso consegue pesar suas qualidades e características elevando o sucesso da sua equipe, segundo Hunter (2004). (Figura 1)

Figura 1. Características identificadas em um líder na qual aumenta o sucesso de uma equipe.

\section{Líder}

\section{Equipe}

Comunicação efetiva

Transmitir transparencia,

confiança e assumir

responsabilidade

Atitudes positivas e

entusiasmadas

Diminuição dos niveis de estresse

Harmonia e satisfação

Encorajar e influenciar seus líderados

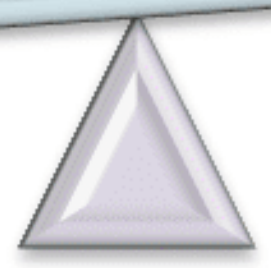

Fonte: Autor.

RC: 89084

Disponível em: https://www.nucleodoconhecimento.com.br/saude/atuacao-dalideranca 
Além de realizar a supervisão, trabalhar a comunicação efetiva, práticas educativas e preventivas para a saúde de sua equipe, é fundamental ficar alerta uma vez que quando desmotivados e abalados irá refletir afetando não só nas funções a serem desenvolvidas, mas também em sua vida diária e relacionamentos. Por isso é estimado que um bom líder seja aquele que esteja preparado possuindo capacidade de instigar o empoderamento de sua equipe envolvendo-os para a prestação de um cuidado seguro e de qualidade, fazendo assim com que os objetivos sejam alcançados, acarretando um efeito positivo. (CARVALHO et al., 2016)

Um estudo referente à fundamentação para compreender os erros de enfermagem evidenciou que algumas questões podem influenciar diretamente no cotidiano do profissional, sendo elas: Força do trabalho que engloba o déficit de profissionais diminuindo a rotatividade e aumentando a sobrecarga trabalho; tais quesitos estão diretamente relacionados com a gestão e organização e, com isso, o índice de imprudência, negligencia e distração entre os profissionais aumenta os incidentes que resultam em erros mostrando uma fragilidade na prestação da assistência, e qualidade do cuidado promovendo práticas involuntariamente incorretas. (FORTE et al., 2019)

O enfermeiro além da arte de cuidar possui uma grande responsabilidade que é gerenciar, tendo com intuito de implementar melhorias, tais como novos métodos educacionais, técnicas e protocolos expandindo sua visão de engajamento afins de obter resultados seguros e qualificados, ainda exercendo sua capacidade de tomada de decisões, com engenhosidade, e inovação com uma visão ampliada de resolutividade (FERREIRA, DALL'AGNOL; PORTO, 2016). O líder que não consegue liderar de maneira eficiente acaba deixando pesar os aspectos negativos da equipe em relação a má gestão. (Figura 2) 
Figura 2. Aspectos negativos acarretados pela equipe relacionados a má gestão.

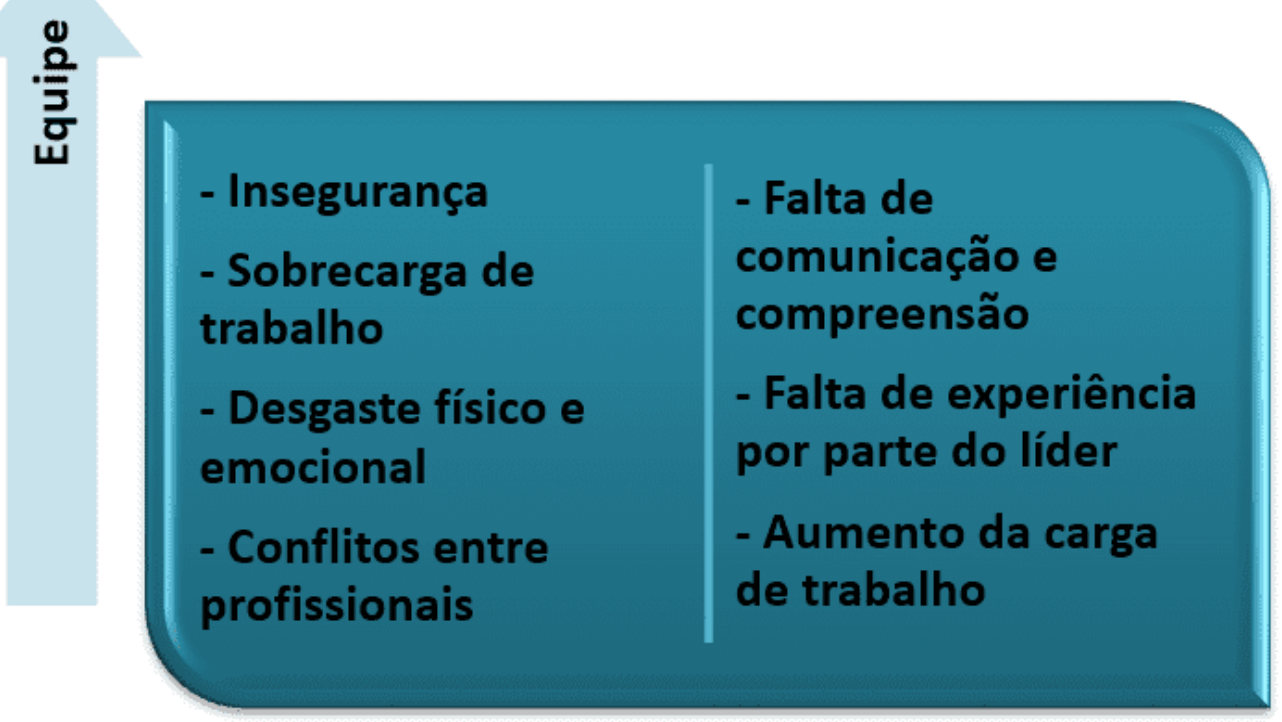

Fonte: Autor.

A relevância de liderar é influenciar pessoas, é saber propor mudanças na equipe visando a melhor assistência reduzindo o mínimo aceitável de danos causados pela sobrecarga de trabalho, utilizando da educação continuada para promover mudanças no atendimento e na qualidade de vida dos seus pacientes e de sua equipe. Preconizar uma boa relação com a equipe tende a cativar uma resposta efetiva gerando harmonia e satisfação e ambiência no trabalho. (KOERICHA et al., 2019)

Portanto é ideal explorar métodos atualizados para conseguir atender as necessidades diretas e indiretas da equipe podendo ser ela psíquica ou física, sendo ideal realizações de ações e atividades no início do plantão ou até mesmo durante, como: ginásticas laborais, técnicas de relaxamento e até mesmo campanhas que utilizam um dia na semana ou mês para ofertar atendimentos de práticas integrativas com massagem de conforto, auriculoterapia, toque terapêutico, meditação com intuito de fornecer relaxamento e melhoria na qualidade de vida e trabalho do colaborador. Sendo essencial, também, garantir uma ouvidoria para esses profissionais, além de 
acolhimento e terapia para manutenção do equilíbrio psicológico, a fim de se tornarse então uma estratégia comunitária com benefício para todos os lados, tanto do colaborador, instituição e principalmente paciente. (DUARTE; GLANZNER; PEREIRA, 2018)

\section{CONCLUSÃO}

O principal intuito é fazer com que o líder busque meios de preservar a saúde mental de sua equipe reduzindo os impactos causados pela pandemia. Uma vez que a Síndrome de Burnout tem sido a principal doença que vem se disseminando entre os profissionais da área da saúde devido à intensa quantidade de demanda, baixa rotatividade dos colaboradores e a sobrecarga de estrese de ter que lidar com algo desconhecido e duvidoso.

Á visto disso é importante estar sempre atualizando condutas para proporcionar o bem-estar do colaborador, buscando a comunicação efetiva, escuta qualificada, além de ser um líder presente e responsável, acolhedor e buscar pela motivação dos mesmos, engajando a equipe através de práticas educativas, ginástica laboral, e feedbacks abertos de ambas partes (tanto gestores e funcionários) de forma que aumente não só o comprometimento da equipe, mas fazendo com que eles se sintam valorizados e ouvidos, garantindo meios de acompanhamento psicológico desses profissionais que possui o aumento de estresse emocional.

Assim sendo, o objetivo do estudo alcançado, onde foi possível identificar na literatura, os impactos gerados pela liderança das equipes de enfermagem, de maneira negativa na qual um líder sem experiência, no qual não consegue desenvolver a comunicação efetiva e compreender sua equipe, e engendrando sobrecarga de trabalho, gerando insegurança, desgaste emocional e físico, conflitos entre os profissionais acarretada pela pressão da pandemia COVID-19 ao contrário de uma liderança preparada pois é necessário saber liderar em um momento complexo de pandemia afins de minimizar o estresse de uma profissão que por si só é estressante. 


\section{REFERÊNCIAS}

BRASIL. Corona vírus Brasil. Ministério da Saúde Brasil, 2020.

CARVALHO, Amanda Gleice Fernandes; CUNHA, Isabel Cristina Kowal Olm; BALSANELLI, Alexandre Pazetto; BERNARDES, Andrea. Liderança autêntica e perfil pessoal e profissional de enfermeiros. Acta Paulista de Enfermagem, 2016.

DUARTE, Maria De Lourdes Custódio; GLANZNER, Cecilia Helena; PERREIRA, Leticia Passos. $O$ trabalho em emergência hospitalar: sofrimento e estratégias defensivas dos enfermeiros. Revista Gaúcha de Enfermagem, 2018.

FERREIRA, Gímerson Erick; DALL'AGNOL, Clarice Maria; PORTO, Adrize Rutz. Repercussões da proatividade no gerenciamento do cuidado: Percepções de enfermeiro. Escola Anna Nery, 2016.

FORTE, Elaine Cristina Novatzki; PIRES, Denise Elvira Pires De; MARTINS, Maria Manuela Ferreira Pereira Da Silva; PADILHA, Maria Itayra Coelho De Souza; SCHNEIDER, Delcinéia Ghizoni; TRINDADE, Letícia De Lima. Processo de trabalho: fundamentação para compreender os erros de enfermagem. Revista de Enfermagem da USP, 2019.

GONÇALVES, Ana Rita; GALVÃO, Ana; ESCANCIANO, Susana; PINHEIRO, Marco; GOMES, Maria José. Stress e engajamento na profissão de enfermagem: Análise de dois contextos internacionais. Revista Portuguesa de Enfermagem de Saúde Mental, 2018.

HOLANDA, Marcelo Alcantara; PINHEIRO, Bruno Valle. Pandemia por COVID-19 e ventilação mecânica: enfrentando o presente, desenhando o futuro. Jornal Brasileiro de Pneumologia, 2020.

HUMERES, Dorisdaia Carvalho De; OHL, Rosali Isabel Barduchi; SILVA, Manoel Carlos Neri Da. Saúde Mental dos Profissionais de Enfermagem do Brasil no 
Contexto da Pandemia COVID-19. Ação do Conselho Federal de Enfermagem. Revista Cogitare Enfermagem, 2020.

JAMES C. H. O monge e o Executivo; tradução de Maria da Conceição Fornos de Magalhães - Rio de Janeiro: Sextante, 2004. Marras, Jean Pierre - Adm.

KOERICHA, Cintia; LANZONI, Gabriela Marcellino De Melo; COIMBRA, Rebeca; TAVARES, Karina Sofia; ERDMANN, Alacoque Lorenzini. Recursos e competências para gestão de práticas educativas por enfermeiros: revisão integrativa. Revista Gaucha de Enfermagem, 2019.

OLIVEIRA, Wanderlei Abadio De; CARDOSO, Érika Arantes De Oliveira; SILVA, Jorge Luiz Da; SANTOS, Manoel Antônio Dos. Impactos psicológicos e ocupacionais das sucessivas ondas recentes de pandemias em profissionais da saúde: revisão integrativa e lições aprendidas. Estudos de Psicologia (Campinas), 2020.

PEREIRA, Mara Dantas; TORRES, Erivelton Cunha; ANTUNES, Paola Fernanda Santos; COSTA, Cleberson Franclin Tavares. Sofrimento emocional dos Enfermeiros no contexto hospitalar frente à pandemia de COVID-19. Human Sciences 22020.

SANTOS, ER e col. O Impacto da Pandemia Covid-19 na Saúde Mental dos Profissionais de Enfermagem do Estado de São Paulo. Unoeste e COREN-SP, 2020.

SILVA, Ana Elisa Bauer De Camargo; CAVALCANTE, Russany Gabrielly Ferreira; LIMA, Juliana Carvalho De; SOUSA, Maiana Regina Gomes De; NUNES, Ranielle De Lima Silva. Avaliação do clima de segurança do paciente em unidades de internação hospitalar: um estudo transversal. Revista de Enfermagem da USP, 2019.

SOARES, Cassia Baldini; HOGA, Luiza Akiko Komura; PEDUZZI, Marina; SANGALETI, Carine; YONEKURA, Tatiana; SILVA, Deborah Rachel Audebert 
Delage. Revisão integrativa: conceitos e métodos utilizados na enfermagem. Revista Escola Enfermagem USP, 2014.

Enviado: Dezembro, 2020.

Aprovado: Junho, 2021. 